\title{
Identidade e memória nikkei: o caso das mulheres japonesas em Santa Maria*
}

\author{
Alexandra Begueristain da Silva** \\ André Luis Ramos Soares***
}

\section{Introdução}

Com a intenção de analisar as adaptações culturais dos imigrantes japoneses residentes em Santa Maria, Rio Grande do Sul, o presente trabalho tem seu foco nas práticas gastronômicas típicas desses imigrantes, que são transmitidas de geração a geração pela oralidade, sobretudo pelas mulheres. O prato típico escolhido para ser analisado, com base nas narrativas das japonesas moradoras de Santa Maria, foi o missô, que carrega um simbolismo especial para os nipo-brasileiros, podendo ser entendido como parte de seu patrimônio imaterial.

Os imigrantes japoneses chegaram a Santa Maria há mais de cinquenta anos (1958), trazendo na bagagem poucos utensílios de cozinha. Provavelmente, conforme citam Kiyotani e Yamashiro, traziam, como seus conterrâneos paulistas, "um frasco de conserva, um molho para temperar a comida, uma ou outra raiz medicinal, pauzinhos (que podem ser de alumínio) para

* Este artigo foi originalmente apresentado na Associação Nacional de História (ANPUH) no ano de 2011, em São Paulo, e traz as contribuições adquiridas no Grupo de Trabalho (GT) História Oral. Foi, assim, revisto e ampliado, sendo este conteúdo original.

** Mestre em Ciências Sociais pela Universidade Federal de Santa Maria (UFSM).

E-mail: alexandrabegueristain@yahoo.com.br.

*** Professor do Programa de Pós-Graduação em História (PPGH) e de Ciências Sociais (PPGCSociais) da Universidade Federal de Santa Maria (UFSM). E-mail: alrsoaressan@gmail.com. 
comer arroz, colheres pequenas, mas largas e chatas, para as refeições” (1992, p. 68). Foram, aos poucos, adaptando-se ao modo brasileiro de cozinhar e utilizar temperos e utensílios, integrando-se, cada vez mais, à cultura brasileira.

O grupo de imigrantes japoneses da cidade de Santa Maria é constituído por 25 famílias. Dessas, cinco participaram da pesquisa. Sendo que oito famílias aderiram à pesquisa sobre a gastronomia nipônica; as demais não participaram desta pesquisa especificamente. Na maioria das vezes, os pesquisadores foram recebidos pelas senhoras de primeira geração (isseis), sempre acompanhadas de suas filhas. Os imigrantes residentes em Santa Maria são oriundos, em sua maioria, da província de Kumamoto, da ilha de Kyushu, no sudoeste do Japão. Esses imigrantes vieram dispostos a trabalhar durante um curto período (quatro a cinco anos) para enriquecer e retornar o mais breve possível ao Japão (Soares e Gaudioso, 2008).

Houve, no entanto, um processo de integração ou, como anteriormente era trabalhado pela antropologia, de "assimilação" cultural. Esse processo se deu à medida que os japoneses foram se adaptando ao paladar brasileiro e, ao mesmo tempo, tentando manter em seus grupos ou colônias alguns traços culturais trazidos do Japão, como é o caso da gastronomia típica e, principalmente, do preparo do missô, foco deste estudo (Shoji, 2002; Sakurai, 2000).

O processo de integração - tratado, neste estudo, como um processo de "abrasileiramento" (Handa, 1987) - tem como base, por um lado, a adaptação do paladar dos japoneses às iguarias típicas do Brasil, aos seus variados temperos e aos alimentos muito diferentes dos utilizados no Japão; por outro, fundamenta-se na construção pelo grupo, com o passar do tempo, de uma identidade que pode ser chamada de étnica ou hifenizada, segundo Lesser (2001) e Hatugai (2009). Assim, mantêm em seu cardápio, após anos de imigração, pratos tipicamente japoneses, entre eles o missô, uma das peculiaridades dessa gastronomia pertencente à identidade hifenizada "nipo-brasileira".

A combinação entre a manutenção de traços gastronômicos tradicionais e a agregação de sabores brasileiros ao paladar japonês configura o que Lesser (2001) chama de negociação da identidade étnica ou construção de uma identidade hifenizada. Diante disso, tem-se o que Carneiro da Cunha (1986) chama de cultura de contraste, definida como o ato de ensinar aos filhos traços culturais que os caracterizam como japoneses, traços esses passados através da oralidade, objeto do presente artigo.

Mesmo que, inicialmente, pretendessem voltar ao Japão em um período não maior do que cinco anos, mantinham dentro do grupo tais características 
diacríticas. Esse retorno, porém, não aconteceu, e, hoje, o missô é preparado somente por poucas mulheres da colônia, correndo o risco desse "saber fazer" se perder com o tempo.

Quando determinados hábitos alimentares e práticas gastronômicas permanecem em um grupo étnico com o passar do tempo, cria-se um cenário gastronômico com certa coerência e integração, formando o que se chama de cozinha típica. Essa cozinha apresenta pratos que, por suas peculiaridades de preparo e degustação, bem como pelos simbolismos que possuem para o grupo, terminam por compor parte do patrimônio imaterial do grupo - os chamados pratos típicos.

$\mathrm{O}$ missô $\hat{O}^{1}$ preparado pelos imigrantes japoneses e seus descendentes constitui um exemplo de prato típico, perpassado de simbolismo e saberes particulares da comunidade nikkei. ${ }^{2} \mathrm{~A}$ despeito da sua importância, apenas uma das cinco senhoras entrevistadas sabe preparar a pasta fermentada de soja, e a tendência é que alguns desses saberes desapareçam, caso não sejam reconhecidos e preservados como patrimônio imaterial da gastronomia nipo-brasileira. Todas as demais compram o missô preparado por ela, o industrializado que se encontra no mercado ou, ainda, o que é trazido de São Paulo. Há uma inquietação entre as imigrantes japonesas de Santa Maria, visto que suas filhas não se preocupam em aprender a fazer tais pratos, o que poderia levar a uma perda do conhecimento e da cultura japonesa. Essas imigrantes não sabem, no entanto, como evitar isso, pois falam, na maior parte do tempo, em japonês e suas filhas não compreendem tão bem o idioma.

1 Missô (味噌), também grafado miso, é um ingrediente tradicional da culinária japonesa feito a partir da fermentação de arroz, cevada e soja com sal. O resultado é uma pasta que, dissolvida em água quente e misturada com alguns vegetais, serve para fazer a sopa de missô ou missoshiru (味噌汁).

2 “O japonês-brasileiro, ou seja, o descendente de japonês é atualmente denominado de nikkei, não importa a que geração pertença. Esta denominação está sendo utilizada desde a Convenção Panamericana Nikkei ocorrida em 1985, em São Paulo, que adotou a terminologia para todos os descendentes japoneses nas Américas. Antes, usava-se a terminologia nissei, para os descendentes dos imigrantes, sansei, para os descendentes de terceira geração no Brasil. Essa terminologia foi adotada na década de 1950, substituindo o termo dainisei (Sakurai, 1993, p. 21) e passou por várias adaptações até ser abandonada em 1982. Uma definição mais atual do termo nikkei foi formulada por Shigeru em 2002: "Os residentes no exterior com nacionalidade japonesa, assim como aqueles que não têm nacionalidade, mas são descendentes de japoneses (primeira geração naturalizado, segunda ou terceira geração)" (Shigueru, 2011). Por tratar-se de palavra estrangeira, optou-se, neste estudo, por utilizá-la sempre no singular, mesmo que, em algumas publicações mais recentes, se possa encontrá-la no plural. Como a palavra nikkei refere-se ao descendente e, normalmente, não ao japonês propriamente dito, neste trabalho denominamos os imigrantes de origem japonesa de "imigrantes" ou "japoneses", pois se trata da primeira geração. Às vezes, diz-se "comunidade nikkei" a fim de englobar imigrantes e descendentes. 
Vale apontar que a única senhora que sabe preparar o missô é nissei, ou seja, pertencente à segunda geração; ela aprendeu em um livro como fazer o prato e, posteriormente, aprimorou esse conhecimento em viagens ao Japão. A senhora M. N., issei, que recebeu gentilmente os pesquisadores em sua casa, com chá verde e manju (doce de feijão), aponta sua preocupação com o envelhecimento do grupo:

É que aqui da Santa Maria... É também que pequeno [a colônia], primeira imigração, mas quer dizer que é um grupo pequeno, cada vez que vai se falecendo, assim né, vai diminuindo de colônia, então que foi assim que da esse tipo de nissei coisa que tudo estuda...vai trabalha, estuda, luta e assim coisa [se esforça], daí que nesse instante que vai ficando longe, né? Daí foi que ficô cada vez mais pequeno, que foi. Então, que pra crescê, não cresce muito, né? (M.N., 2012).

\section{Patrimônio imaterial nikkei}

Historiadores, antropólogos, sociólogos e outros estudiosos brasileiros e estrangeiros há várias décadas vêm discutindo sobre o entendimento e as estratégias de proteção do patrimônio cultural (Tamaso, 2005). Dentre as contribuições mais relevantes para essa discussão, pode-se citar o reconhecimento pela Organização das Nações Unidas para a Educação, a Ciência e a Cultura (UNESCO) dos chamados bens imateriais. Muitos desses bens, também conhecidos como bens culturais,

que compõem um patrimônio estão associados ao 'passado' ou à 'história' [...]. Eles são classificados como 're líquias' ou 'monumentos'. Assim como a identidade de um indivíduo ou de uma família pode ser definida pela posse de objetos que foram herdados e que permanecem na família por várias gerações. (Gonçalves, 1988, p. 267).

A UNESCO reconhece como amostras de patrimônio cultural imaterial as tradições, o folclore, os saberes, as técnicas, as línguas, as festas e diversos outros aspectos e manifestações, transmitidos de forma oral ou gestual, recriados coletivamente e modificados ao longo do tempo (Tamaso, 2005). O patrimônio imaterial é, assim, transmitido através das geraçôes e pode 
ser recriado e reelaborado pelos grupos sociais e étnicos em função de seu ambiente sociocultural, de sua interação com a natureza e de sua história, provocando um sentimento de identidade, de autodefinição e de prosseguimento das características do grupo. Ainda sobre as definições do que pode ser reconhecido como patrimônio imaterial - e trabalhado sob a perspectiva de variadas áreas do conhecimento -, observe-se a afirmação de Tamaso:

Uma diferença há e não é de objeto, mas sim epistemológica. Transforma-se o modo como se 'olha' para o objeto. Manifestaçôes culturais (dança, música, poesias, crenças, expressões, técnicas etc.), encaradas por folcloristas, são 'folclore, 'fato folclórico', 'manifestação folclórica'. Aos olhos dos antropólogos, são 'cultura'. Atualmente, a tendência de ambos é de percebê-los como 'patrimônio'; ao menos pelo fato de que, ao serem potencialmente bens patrimoniais, ampliam as possibilidades profissionais de ambos. (Tamaso, 2005, p. 17).

Londres (2004), citando o anteprojeto da UNESCO aprovado na $32^{\text {a }}$ Conferência Geral, realizada em outubro de 2003, traz a seguinte definição de patrimônio imaterial:

O 'patrimônio cultural intangível' é constituído por práticas, representações, expressões, saberes e fazeres - assim como instrumentos, objetos, artefatos, e espaços culturais que lhe são associados - que comunidades, grupos e, quando for o caso, indivíduos reconhecem como parte de sua herança cultural. Esse patrimônio cultural imaterial, transmitido de geração em geração, é constantemente recriado por comunidades e grupos em resposta ao seu meio ambiente, sua interação com a natureza e suas condições históricas de existência, e lhes proporciona um sentido de identidade e continuidade, promovendo assim o respeito pela diversidade cultural e pela criatividade humana. (Londres, 2004, p. 22-23).

Desse modo, percebe-se que a culinária pode ser considerada como parte integrante do patrimônio cultural imaterial. O preparo, por exemplo, do missô, indispensável à culinária japonesa, e todo o seu modo tradicional de fazer possuem grande relevância, uma vez que representam um "saber fazer", um traço diacrítico que faz os indivíduos ainda japoneses, mesmo que longe do Japão. Ao encontro disso, Hatugai afirma que: 
Brasi-nipônicos, ou seja, ‘japoneses' que ao se tornarem 'brasileiros' produziam um sentido novo, não uma terceira via ou uma crise em seu jeito de ser; são aqui brasileiros e japoneses sem ter que abdicar ou decidir somente por uma identificação como um sentido que expressa esses estados em suas vivências cotidianas. De maneira que os sentidos que compunham tal japonesidade na vida da associação estavam, principalmente, baseados em cultivos da 'tradição' que os imigrantes trouxeram expressos, por sua vez, em festividades, sociabilidades entre as famílias e os valores agregados a ela, no uso da língua japonesa como um ideal, e em noções de substância pensadas na ordem dos 'alimentos' e no símbolo do 'sangue' como descendência japonesa (Hatugai, 2011, p. 61; grifo nosso).

A cultura gastronômica constitui-se, desse modo, como uma importante representação da identidade étnica, adentrando o imaginário pela via dos sentidos (olfato, paladar e visão). Os japoneses prezam os sentidos, dão valor aos prazeres, como dormir, tomar um banho quente e, claro, conforme pressupõe o foco deste trabalho, comer, degustar os sabores. Ruth Benedict lembra que:

Comer, tal como o agasalho e o sono, tanto é um repouso abertamente desfrutado como prazer, quanto uma disciplina imposta para adquirir-se têmpera. Como forma de lazer, os japoneses demoram-se em refeições com infindáveis pratos, durante as quais uma colher de chá de alimento vem de cada vez e a comida é apreciada tanto pelo aspecto como pelo sabor. Mas a disciplina, por outro lado, é exigida. (Benedict, 2002, p. 155).

Essa característica ainda é preservada pelos japoneses de Santa Maria, pois apreciam os momentos de convivência entre o grupo, no qual se reúnem as diferentes geraçóes e ainda são servidos pratos japoneses e brasileiros. Durante a pesquisa, ouviram-se, por exemplo, relatos de que os netos pedem às avós que preparem tanto sushi como churrasco para o almoço de domingo. Porém, como observa Benedict (2002), a autodisciplina, característica da cultura japonesa, também pode levar à privação dos sentidos e da alimentação.

A cultura de um grupo étnico é transmitida, principalmente, de forma oral, de geração a geração, com base na memória, e no caso da gastronomia não é diferente. Mesmo passados alguns anos da imigração, os pratos servidos 
nas casas dos imigrantes tentavam reproduzir a alimentação à moda japonesa, ao mesmo tempo em que assimilavam os temperos brasileiros, conforme conta Handa (1987).

Com relação à identidade desses imigrantes ver também Lesser, 2001, é relevante atentar para as colocações de Handa:

Mesmo depois de passar cerca de dez anos no Brasil os primeiros imigrantes não haviam conseguido aprender o modo de temperar a comida. Depois de tanto tempo já se fazia missô nas fazendas. O shôyo ${ }^{3}$ era vendido apenas nas cidades, o que significava que só começou a aparecer quando os japoneses, com o aumento de sua população, começaram a procurar as cidades para as suas moradias. Nos primeiros tempos, utilizava-se como substituto do shôyo o caldo que sobrava no barril de missô. Só depois de 1915, com o aparecimento de jornais, é que iriam saber de sua existência.

Um prato sem tempero ou sem shôyo, mas feito com ingredientes brasileiros, era algo realmente esquisito. Só o feijão no início foi assimilado, por constituir a base da alimentação brasileira. Mas, o recém-chegado do Japão tinha o costume de cozinhá-lo com açúcar. (Handa, 1987, p. 108).

É interessante lembrar todo o simbolismo que carrega a alimentação. Um dos autores que se debruçou sobre esse tema no Brasil foi DaMatta (1987), que chegou à conclusão de que "qualquer brasileiro sabe que toda substância nutritiva é 'alimento', mas sabe também que nem todo alimento é 'comida'. De fato, para transformar um alimento em comida, é preciso não só o ato crítico do cozimento, mas também o modo pelo qual o alimento é preparado" (p. 22), oque indica o simbolismo e a importância do modo de preparo do alimento que fará parte da gastronomia de um grupo.

$\mathrm{O}$ ato de alimentar-se, do ponto de vista que orienta este estudo, possui um caráter muito especial, uma vez que existe um comportamento simbólico no que diz respeito à alimentação humana que "revela repetidamente a cultura em que cada um está inserido" (Mintz, 2001, p. 32). As diferentes maneiras de comer desvelam as culturas dos diferentes grupos, e as concepções e classificações por eles estabelecidas informam acerca de suas visões de mundo, bem como de sua organização social. $\mathrm{O}$ ato de comer está, também,

3 Molho produzido pela fermentação da soja e da cevada, com adição de sal. 
diretamente relacionado à sobrevivência biológica do homem; trata-se de um ato vital (Maciel, 2001).

Quanto ao missô, alimento consumido pelos imigrantes japoneses em festas e datas especiais, Handa observa que

era fabricado em casa e às vezes também o shôyu (embora na época já estivesse à venda). A refeição consistia de arroz branco e missoshiro (sopa de missô) e vegetais em conserva. $\mathrm{O}$ vegetal em conserva era preparado com fubá em substituição ao nuka de farelo de arroz. Havendo estes três pratos o resto poderia ser uma comida brasileira ou de qualquer outro lugar. Ainda não tinham o hábito de cozinhar o feijão diariamente. Livres da obrigatoriedade de submeter-se aos costumes estritamente brasileiros das fazendas, houve uma retomada do estilo japonês, comendo-se basicamente o arroz branco e tempero à base de shôyu e missô, embora introduzindo vários ingredientes brasileiros. Não dispensavam, por exemplo, o uso da banha de porco, usavam continuamente o alho e bebiam café, que eram hábitos adquiridos nas fazendas e que persistiram mesmo depois que se mudaram para os núcleos. Às vezes cozinhavam arroz temperado e feijão, especialmente para os camaradas brasileiros. As crianças comiam esse arroz e acabaram se habituando com o paladar brasileiro. No preparo da carne utilizava-se óleo, mas sua inclusão no tempero teve muita resistência. Entretanto nas festas de casamento e nas festividades de ano novo, a alimentação voltava a ser totalmente à japonesa. (Handa, 1987, p. 239).

Cabe ressaltar ainda que a gastronomia também tem importante papel na construção/manutenção da identidade étnica, por ser capaz de preservar traços culturais anteriores à imigração e desenvolver um sentimento de pertença étnica e autoafirmação cultural. Mesmo que a palavra preservação venha repleta de ressalvas, visto que a culinária japonesa se misturou à brasileira, tem o poder de expressar parte desse processo de renegociação da etnicidade de grupos imigrantes (Carneiro da Cunha, 1986; Lesser, 2001).

A partir da gastronomia, do preparo do missô e de tudo que pode ser considerado patrimônio cultural, pode-se pensar o grupo étnico como uma unidade real, autônoma, dotada de identidade, caráter e memória, capaz de valorizar e transmitir seu patrimônio para seus descendentes. Contudo, para definir a identidade de grupos étnicos, é interessante trazer o conceito que Zanini (2005) atribuiu à identidade étnica ao trabalhar italianidade com 
descendentes de imigrantes italianos na região central do Rio Grande do Sul: para a autora, a identidade étnica permite que o sujeito realize uma discursividade sobre si, de maneira que os elementos simbólicos e afetivos possuem importância bastante acentuada. Esses elementos são tomados de empréstimo do mundo dos antepassados, considerados sagrados (Silva, 2013).

A transmissão dos saberes e mesmo dos valores japoneses dos imigrantes aos nisseis é feita através da oralidade. A educação é brasileira, mas as suas raízes, conforme Kiyotani e Yamashiro, não são esquecidas:

Seja qual for a forma de emigração, a maioria terá que morrer na terra para onde emigrou, logo a educação de dainisei (nisei) deve ser a local, ou seja, a brasileira. Não há necessidade de impor o espírito de reverência ao imperador e amor à pátria (japonesa). Será perfeito se formar cidadãos conscientes de seus deveres, corajosos e honestos; então teremos uma segunda geração (filhos de japoneses) dos quais não precisamos nos envergonhar. Só uma coisa: é preciso ensinar bem a língua japonesa. (Kiyontani; Yamashiro, 1992, p. 100).

Os nikkei de Santa Maria também pensam e se manifestam assim. A maioria de seus filhos compreende o japonês, mas, ao terem de se dedicar, se superar e se destacar na escola, muitos desses jovens optaram pela cultura brasileira e seus valores. Desse modo, não reproduzem tal e qual os costumes de seus pais, nem no que se refere à culinária nem em outros aspectos, como a religiosidade familiar - tema estudado, por exemplo, por Silva (2013). Em uma das narrativas colhidas para este estudo, uma entrevistada da segunda geração justifica sua escolha pela religião católica:

Sou batizada, mas não sou registrada. Os grandes não foram batizados, eram só as crianças... porque a gente ia escola, ia à igreja. $\mathrm{Na}$ escola, quem não fosse católico ficava do lado de fora [na aula de ensino religioso], acho que ainda é assim, não sei, é discriminação daí, né... então se era católico podia assistir a aula. A gente tem uma facilidade... que é considerado assim... um pouquinho melhor que negro, que cafuzo e índio, assim... e é diferente, e dizem que é mais inteligente, aquela coisa assim... A gente tinha mais amigos, não era discriminado no mau sentido, era discriminado no sentido que todo mundo queria andar com a gente porque a gente era diferente. Então era assim, a gente ficou católico assim, depois seguiu, né... (T.K., 2012). 
T. K. é nissei e trabalha como enfermeira no Hospital Universitário de Santa Maria. Nas visitas dos entrevistadores à sua sala no hospital e, posteriormente, à sua casa, ofereceu-lhes café preto, bebida típica no Brasil, diferentemente do que ocorreu em outras residências, onde se oferece chá verde, bebida típica no Japão.

Quanto à alimentação japonesa, ela está presente na vida da segunda e terceira geração, mas de forma simbolizada. Assim, a comida que os antepassados gostavam é colocada no oratório doméstico, ainda que os jovens possam não entender o significado desse ritual. Não sabem, tampouco, preparar o missô ou outras iguarias típicas da culinária japonesa; daí a importância de salvaguardar a memória das mulheres nikkei como patrimônio imaterial para continuar compondo a identidade étnica do grupo nas futuras gerações.

Para os japoneses de Santa Maria, o missô, bem como outras iguarias dessa culinária, sempre está presente em eventos e cerimônias da comunidade nikkei na cidade. Ainda assim, alguns costumes não persistiram nas novas gerações, como aponta a senhora M. N., ressaltando que não sabe o que é preciso fazer para transformar essa realidade: "sabem de eu ouvi, ouve, mas que foi de assim [...]. Por isso assim que tem diminuindo, entende? Então que fica, não sei o que é que vai se preciso aqui” (M. N., 2012).

Hatugai (2011) destaca a importância das mulheres nessa transmissão de saberes culturais, por meio do que é conhecido como "baatianês" ou língua das avós, o que denota a responsabilidade que recai sobre as mulheres de assegurarem algum conhecimento acerca da gastronomia japonesa para seus filhos e netos. Além disso, fica evidente, também, a questão da hierarquia familiar e do respeito dos mais novos em relação ao saber dos mais antigos:

A definição dada por Lucas [interlocutor de Hatugai] para a língua da 'colônia’ ou dos descendentes era cara e apontava para duas questóes: a primeira delas, que eram os mais velhos, notadamente a avó, os elos de continuidade de algumas características 'japonesas' na família. A segunda questão era que o japonês falado no cotidiano não deveria ser pensado em termos de comparação com um japonês fluente ou perda da 'tradição', mas como a língua 'japonesa' advinda da presença imigrante, aprendida na família e interpretada como uma especificidade 'japonesa' comunicável entre as diferentes gerações de descendentes. (Hatugai, 2011, p. 69). 
Hatugai explica ainda que a gastronomia atua como elemento de preservação dos costumes e da identidade cultural dos nikkei, ou do que ela chama de japonesidade, principalmente dentro das famílias e associações, nas quais mesmo quem não fala japonês - como os mais jovens - aprende a apreciar os sabores da terra de seus ancestrais por meio das memórias de suas mães e avós.

A 'comida japonesa' era um dos elementos que mais emergiam devido à sua associação à 'preservação dos costumes', e nessa reprodução a 'comida' também evidencia a questão geracional acerca dos saberes e cuidados que os mais velhos empreendem no interior das famílias, em especial a presença e os cuidados das mulheres mais velhas. (Hatugai, 2011, p. 71).

Para Hatugai, a vida em comunidade exige dos descendentes de japoneses alguns comportamentos que lhes são atribuídos por outros naturalmente, diante da história e da tradição do povo japonês. "A 'comida japonesa' entra nessa ordem de comportamentos e práticas 'inatas' à vida dos descendentes através do consumo do alimento, ratificando e promovendo japonesidades" (Hatugai, 2011, p. 77). A categoria "inata" está sugerindo o caráter eminentemente simbólico da construção do que é a niponicidade ou a identidade nipo-brasileira no contexto da imigração, aos moldes de Hatugai (2011) e Lesser (2001).

A culinária japonesa, seus ingredientes e suas formas de preparo não são reproduzidos somente através da oralidade. Em alguns casos, observa-se a busca em outras fontes de informações sobre essa culinária devido a fatores culturais, sociais e medicinais ou, simplesmente, devido a fatores ligados à tradição. Em relação a isso, a senhora R. I., nissei, quando indagada sobre se havia aprendido a fazer missô com a sua mãe ou a sua sogra, respondeu:

Não, eu li o livro, e minha [mãe] fazia, mas quando a minha mãe fazia eu não ligava nem um pouco, depois é que a gente começa, né [...]. Minha mãe tomou missoshiro todo santo dia, sem mentira nenhuma, ela faleceu com quase noventa e seis anos, desde pequena a alimentação dela foi assim, criou sete filhos, amamentou outros e o que que ela comia? Não tinha carne todos os dias, não tinha essas coisas...

Nissei, a senhora R. I. aproveitou o livro que ganhou de sua mãe (Arte culinária japonesa, escrito em português), bem como as suas visitas ao Japão, 
para aprender os segredos do feitio do prato. Relatou ainda que, da mesma forma, sua filha também não aprendeu o preparo do missô: "Não... mas nem tá... é assim... 'cê pensa que faz milagre em casa? Mas ela come, ela sabe como se prepara, sabe porque se usa, mas fazer nunca.... Tal fato pode indicar que nem sempre o grupo reconhece seus saberes como patrimônios.

Em entrevista com a senhora K. N. (2011), ela também conta como aprendeu as receitas japonesas. Nascida no Japão, veio com doze anos para o Brasil, na década de 50, chegando a Santa Maria, como as demais famílias, em 1958. A entrevistada lembra sua mãe cozinhando: "sim... aprendeu com a mãe, aprende com amigas, o nosso grupo, as japonesas, aprende assim, já faz tempo, tanto anos aqui né, sabe comida japonesa.... Relatou que, apesar disso, compra o missô preparado pela senhora R. I. - e que várias outras senhoras fazem o mesmo.

K. N. recorda ainda as dificuldades enfrentadas quando chegou ao Brasil, contando que a mãe trabalhava muito na lavoura, mas também precisava cozinhar:

Trabalhou demais, mais do que homem, ficou doente, com reumatismo[...], trabalhou muito, trabalhava cozinhando, naquela época, antigamente tudo difícil, nós trouxemos do Japão, veio de navio, bastante coisa trouxemos, mas aí terminava, não dava para comprar, ela sofreu bastante, barbaridade, e aí a mãe fazia missô, fazia shoyo.

Percebe-se que essas são narrativas que relacionam a gastronomia às memórias da infância no Japão e dos sofrimentos na chegada ao Brasil; associam-na ainda às memórias de um "saber fazer" particular, que compõe a identidade étnica nipo-brasileira. São recortes de lembranças muitas vezes adormecidas e despertadas no sujeito durante a conversa com o investigador. É imprescindível que o pesquisador estabeleça uma relação de confiança com o sujeito investigado para que possa fazer com que as lembranças transmitidas pela oralidade aflorem e essas pessoas percebam que suas reminiscências têm o mesmo grau de importância das fontes escritas.

Portelli (1997) ressalta a importância do diálogo e do papel da história oral e julga, inclusive, que cabe à história o desafio de renovar a questão do diálogo. Mas seria a função da história oral apenas a preservação da oralidade? O autor afirma que a função da história oral passa pelas relações de poder estabelecidas dentro da academia, tendo uma finalidade que difere 
da história tradicional, uma vez que seu intuito é registrar não a única, mas uma das possíveis versões da realidade, contada sob o ponto de vista de grupos minoritários, anônimos, invisíveis a uma história tradicional. Ressalta-se ainda que a amarração das histórias de vida desses grupos pode ser feita por diversas perspectivas, sejam antropológicas, sociológicas, históricas ou outras, através da leitura de cada pesquisador. Neste estudo, optou-se por um olhar antropológico sobre a cultura gastronômica das imigrantes japonesas e seus saberes e fazeres.

\section{A memória nikkei}

A discussão sobre identidade leva à discussão acerca do conceito de memória. Segundo Halbwachs (1990), a memória divide-se em dois tipos: a memória individual e a memória coletiva, mutuamente interferentes. A memória individual é aquela que toda pessoa possui, referente ao que ela viveu ao longo de sua vida, ou seja, às lembranças individuais. Já a memória coletiva

Envolve as memórias individuais, mas não se confunde com elas. Ela evolui segundo suas leis, e se algumas lembranças individuais penetram algumas vezes nela, mudam de figura assim que sejam recolocadas num conjunto que não é mais uma consciência pessoal. (Halbwachs, 1990, p. 53).

A identidade, segundo Lesser (2001) e Zanini (2005), pode ser considerada como algo abrangente, pois é composta não só pela memória coletiva, mas também pelos saberes e fazeres da comunidade, pelo seu patrimônio cultural. Com base nessa discussão, o missô pode ser entendido como parte do patrimônio cultural imaterial da comunidade nikkei, uma vez que representaa própria identidade étnica dos imigrantes e seus descendentes, ainda que nem todos tenham se dado conta da importância desses saberes.

Cabe atentar ainda para a preocupação dos membros da comunidade ${ }^{4}$ nikkei em preservar sua cultura e sua identidade étnica, como se pode obser-

4 Esta pesquisa foi realizada com oito famílias de imigrantes de Santa Maria, pertencentes, inicialmente, à Associação de Japoneses que funcionava na cidade. Ainda que a instituição Nihonjinkai (Nihon=Japão; jin=pessoa; kai=associação) tenha sido fechada no ano de 2012, o grupo de japoneses residentes em Santa Maria continua reunindo-se periodicamente. 
var na fala da senhora M. N., em entrevista concedida a estudo já publicado: "Eu gostaria de transmitir bem as nossas tradições, mas é difícil. Se bem que gostaria de transmitir tudo que for possível da tradição japonesa. É realmente muito difícil" (Soares; Gaudioso, 2008, p. 45).

Inagaki (2002) destaca a importância da Colônia Japonesa, a qual delimita traços diacríticos, mas pode não se configurar, como no caso de Santa Maria, em uma única localidade que aglutine todos os moradores de mesma ascendência. Assim, eles podem morar afastados, de modo que é o sentimento de coletividade que os une por terem, nesse caso, vindo do Japão no mesmo navio e terem ido para mesma fazenda em Uruguaiana, Rio Grande do Sul, antes de serem recebidos em Santa Maria. ${ }^{5}$

Pode-se perceber a vontade de passar adiante as tradições - dentre as quais certamente está a culinária -, principalmente por meio da memória e da oralidade. É através dos saberes, das lembranças e das mãos femininas que o alimento atua como elemento determinante na construção de uma identidade étnica.

Observe-se, a afirmação de Inagaki, pesquisadora nissei:

[... a minha ex-sogra botou na cabeça que eu devo ser a 'herdeira' dela para fazer o missô e desde a semana passada estou mexendo com o koji (sementinha dos fungos) e segunda ou terça-feira vamos cozinhar a soja, moer com o koji, misturar tudo com sal e deixar descansar por uns três meses, tendo que semanalmente mexer a massa... e além disso, tendo que aprender a fazer os curtidos de lakiyo (cebolinha miudinha de cabeça) e de gengibre. ${ }^{6}$ (Comunicação pessoal).

Nessa narrativa é perceptível a resistência por parte de algumas nikkei em aprender a fazer o missô com as mulheres mais velhas e, também, a responsabilidade que carregam por serem consideradas herdeiras desse saber. Essa resistência ocorre em função de vários motivos, como o tempo e o trabalho necessário ao preparo da pasta, além da dificuldade de compreender o idioma japonês. Nesse contexto, para que não se perca o "saber fazer", uma das

5 A primeira leva de famílias japonesas que veio diretamente ao estado do Rio Grande do Sul dirigiu-se à cidade de Uruguaiana. Por quebra de contrato e outros fatores, as famílias vieram em conjunto para Santa Maria (Soares; Gaudioso, 2008). 
características da cultura japonesa e de sua tradicional hierarquia (Benedict, 2002) é que a nora aprenda os costumes familiares da sogra, pois, casada, pertence à família do marido (Silva, 2013).

A memória do grupo é construída pelo recorte de lembranças pertencentes aos membros da comunidade, que são os detentores das informações:

Considerando que esse Patrimônio é constituído, sobretudo, pelas diversas memórias do grupo que a representa, vale refletir sobre o título de patrimônio imaterial [...]. Ao terem suas crenças, seus saberes, suas representações, formas de ser, de viver, e de fazer, tomados como patrimônios [...], esses grupos têm que necessariamente assimilar aos seus cotidianos o fato de que são produtores e/ou detentores das memórias que constituem o patrimônio cultural imaterial [...], o que certamente difere do fato de serem portadores de memórias que reconstroem seus saberes e tradições. (Costa; Castro, 2008, p. 127).

Vale ressaltar a importância do papel das emoções na preservação das memórias. Costa e Castro (2008) colocam algumas questões que devem ser ponderadas acerca das emoções e sensações de quem transmite as memórias, daqueles a quem cabe dar continuidade aos patrimônios culturais imateriais, valorizando-os e preservando-os:

Como registrar os bens imateriais escolhendo apenas alguns bens simbólicos a eles associados, sem engessar seus conteúdos, as sensações, os sentimentos e emoções tão necessários à preservação dessa cultura imaterial e sem fazer com que esses costumes e tradições, formas de fazer e saber se fixem e percam o potencial de reconstrução no presente? É possível dar continuidade a um fazer, um saber ou um modo de viver sem cair no erro de se impor sobre a dinâmica própria que essas comunidades ou grupos possuem quanto à continuidade, manutenção e preservação de suas tradições e costumes? (Costa; Castro, 2008, p. 126).

Como já pontuado anteriormente, o patrimônio imaterial é substancialmente constituído por memórias coletivas, que operam com grande liberdade escolhendo acontecimentos no espaço e no tempo - essa escolha não é arbitrária, mas orientada por índices comuns que relacionam esses acontecimentos. Desse modo, como salienta Bosi (2003, p. 31), “é tarefa do cientista 
social procurar esses vínculos de afinidades eletivas entre fenômenos distanciados no tempo". A patrimonialização dos bens culturais deve ter como foco, sobretudo, ações que não solidifiquem as memórias do grupo e nem operem em sentido inverso ao da lembrança pessoal. "Pela memória, o passado não só vem à tona das águas presentes, misturando-se com as percepções imediatas, como também empurra, 'descola' estas últimas, ocupando o espaço todo da consciência” (Bosi, 2003, p. 36).

As políticas e ações culturais em prol da preservação de bens imateriais devem ampliar as concepçóes de vida sem excluir a diversidade cultural, sem modelar a forma de preservação das lembranças e sem desqualificar os modos de passar conhecimentos e saberes tradicionais. Como patrimônio, esses saberes, costumes e modos de viver se ancoram em memórias que circulam, física ou metaforicamente (Costa; Castro, 2008, p. 130), entre os integrantes da comunidade ou do grupo e, para serem conservados e preservados, devem permanecer, simultânea ou aleatoriamente, nas lembranças e recordações de todos. Assim, a preservação desses bens deve ocorrer de maneira que cada sujeito possa registrar sua representação, contribuição, versão ou interpretação, expressando o sentimento de pertença identitária.

Essa preservação ocorre entre as famílias japonesas residentes em Santa Maria por meio de relatos, vestimentas, fotos antigas, instrumentos da culinária que hoje foram substituídos por outros mais modernos - como o "pilão", com o qual se fazia mochi (bolinho de arroz) - e fitas de vídeo das festas típicas - como Engekai e Undokai, ${ }^{7}$ realizadas na chegada a Uruguaiana e Santa Maria -, entregues ao Memorial de Imigração e Cultura Japonesa do Rio Grande do Sul, ${ }^{8}$ com sede na Universidade Federal de Santa Maria, para que os imigrantes tenham um lugar onde salvaguardar suas memórias. Todavia, não se verificou nos relatos o entendimento do preparo do missô como patrimônio imaterial, somente uma imensa vontade de passar adiante o conhecimento culinário, entre outros costumes, para as futuras gerações, pois

7 Engekai é um festival artístico que a comunidade realiza, com apresentações de dança, música, performance, sem cunho competitivo; Undokai é uma gincana poliesportiva. Ambos ainda acontecem, reunindo a comunidade japonesa no estado do RS.

8 O Memorial foi fundado em 2008, a fim de registrar, documentar e salvaguardar a história e a cultura dos imigrantes japoneses no estado do RS. A iniciativa foi partiu de dois professores, da UFSM e da UFRGS, e consistia em recuperar a história dos imigrantes a fim de promover a valorização da imigração no estado. É mantido pelas universidades envolvidas, e sua missão é divulgar elementos culturais japoneses trazidos pelos imigrantes. 
as entrevistadas sabem que, diante o envelhecimento da "colônia" japonesa em Santa Maria, esses saberes podem se perder.

\section{Considerações finais}

Após um século de imigração japonesa no Brasil, faz-se necessária a valorização dos conhecimentos e saberes desse povo, tanto entre a comunidade japonesa de Santa Maria como entre aqueles que pesquisam o assunto. Mas como se protegem, por exemplo, rituais, festas, conhecimentos e habilidades, música tradicional, gastronomia? Isso pode ser feito através de documentos, de pesquisa e trabalho de campo, de registros audiovisuais, da consideração da legislação vigente ou de medidas legais para a sua proteção. Esses materiais poderiam ser incluídos em catálogos da cultura.

Registrar os saberes, as tradições e as adaptações que os imigrantes vivenciaram ao longo dos cem anos de presença no Brasil é uma das tarefas do Memorial de Imigração e Cultura Japonesa do Rio Grande do Sul. Pretende-se, com isso, não somente obter o reconhecimento e a valorização do grupo étnico e das suas contribuições à diversidade cultural do Brasil, mas principalmente registrar sua história, suas memórias e suas formas de relações sociais e culturais. Assim, a proposta de registro da confecção do missô como patrimônio imaterial dos nikkei é o primeiro passo para a salvaguarda dessa e de tantas outras contribuições nipônicas à sociedade brasileira.

A tarefa de costurar as memórias dos sujeitos e amarrar esses recortes à memória coletiva, com a intenção de salvaguardar e garantir a transmissão desses conhecimentos do passado, é o papel do presente em relação ao futuro e está sendo fonte de pesquisas em diversas áreas do conhecimento, como na antropologia, por tratar dos traços diacríticos que compõem esse grupo de indivíduos. O trabalho com a história oral deve ser, sobretudo, uma ultrapassagem da história totalizante e da busca por uma verdade absoluta a partir das narrativas; deve dar espaço a pessoas comuns para que contem suas histórias e suas memórias. Cabe lembrar que nem sempre, no entanto, o ato de rememorar é fácil ou saudável para o sujeito, pois pode trazer à tona lembranças indizíveis, ou dolorosas, mas capazes de levar a outro olhar na história, a um olhar humano dos anônimos. 
Essa postura em relação à história oral supõe a necessidade de gerar alternativas que deem voz aos grupos, incluindo aí as nações que, de uma forma ou de outra, foram silenciadas. Além disso, supõe a "superação" da história oral, tornando-a um "lócus multidisciplinar", que leva à criação de uma nova disciplina.

Nosso objeto de pesquisa são mulheres nikkei da cidade de Santa Maria que contam suas recordações sobre a família, a infância e, principalmente, a gastronomia, recordando o trabalho na agricultura e as dificuldades na chegada ao Brasil, bem como o sofrimento e o processo de superação pelo qual passaram. Evidentemente, quando se trata de história oral, é impossível evitar o encontro com as análises e as críticas sobre a legitimidade das fontes consultadas. De fato, alguns autores não desconsideram a parcialidade da fonte oral. No entanto, tais críticas podem ser revidadas, como faz Joutard (1999), por exemplo, ao afirmar que o que é verdadeiro para um sujeito o é com maior razão para uma coletividade, cuja capacidade para elaborar sua história oficial é muito forte.

Esta pesquisa, ainda em fase preliminar, pretende continuar escutando as memórias das nikkei de Santa Maria, tendo como método a história oral a fim de reconhecer a identidade étnica das nipo-brasileiras, narradas pelas imigrantes de primeira e segunda gerações, respeitando o olhar de cada uma delas na construção de seu discurso. Afinal, não se tem aqui a intenção de chegar a uma verdade absoluta sobre as nikkei de Santa Maria baseada na história oral, mas de trazer ao público as diferentes versões e verdades que possam existir submersas em suas lembranças, trazidas à tona no momento de ensinar o preparo do missô.

\section{Referências}

BENEDICT, Ruth. O crisântemo e a espada. São Paulo: Brasil Perspectiva S.A., 2002. (Debates - Antropologia).

BOSI, Ecléa. O tempo vivo da memória: ensaios de psicologia social. São Paulo: Ateliê, 2003.

CARDOSO, Ruth Corrêa Leite. Estrutura familiar e mobilidade social: estudo dos japoneses no estado de São Paulo. São Paulo: Kaleidos; Primus Comunicação, 1998.

CARNEIRO DA CUNHA, M. Antropologia do Brasil: mito, história e etnicidade. São Paulo: Brasiliense, 1986. 
COSTA, Marli Lopes da; CASTRO, Ricardo Vieiralves de. Patrimônio Imaterial Nacional: preservando memórias ou construindo histórias? Estudos de Psicologia, Natal, v. 13, n. 2, p. 125-131, maio/ago. 2008. Disponível em: <http://www.scielo.br/pdf/epsic/v13n2/04. pdf>. Acesso em: 21 jul. 2013.

DAMATTA, Roberto. Sobre o simbolismo da comida no Brasil. O Correio da UNESCO, Rio de Janeiro, v. 15, n. 7, p. 22-23, 1987.

GONÇALVES, José Reginaldo. Autenticidade, memória e ideologias nacionais: o problema dos patrimônios culturais. Estudos Históricos, Rio de Janeiro, v. 1, n. 2, p. 264-275, 1988.

HALBWACHS, Maurice. A memória coletiva. São Paulo: Vértice, 1990.

HANDA, Tomoo. O imigrante japonês: história de sua vida no Brasil. São Paulo: T.A. Queiroz; Centro de Estudos Nipo-Brasileiros, 1987.

HATUGAI, Érica Rosa. A cultura em movimento e as noções de especificidades locais: imigrantes japoneses e seus descendentes. ENCONTRO ANUAL DA ANPOCS, 33, 2009, Caxambu. Disponível em: <http://portal.anpocs.org/portal/index.php?option=com_ docman\&task=doc_view\&gid=2043\&Itemid=229>. Acesso em: 30 jul. 2013.

Alimentando japonesidades: tradição e substância em um contexto associativo nipodescendente. In: RENÓ, Igor Machado (Org.). Japonesidades multiplicadas: novos estudos sobre a presença japonesa no Brasil. São Carlos: EdUFSCar, 2011.

INAGAKI, E. M. Dourádossu: caminhos e cotidianos dos nikkei em Dourados (décadas de 1940, 1950 e 1960). 164 p. Dissertação (Mestrado em História) - UFMS, Dourados, MS, 2002.

JOUTARD, P. Esas voces que nos llegan del pasado. Ciudad de México: Fondo de Cultura Económica, 1999.

KIYOTANI, Masuji; YAMASHIRO, José. Do Kasato-Maru até a década de 1920. In: COMISSÃO DE ELABORAÇÃO DA HISTÓRIA DOS 80 ANOS DA IMIGRAÇÃO JAPONESA NO BRASIL. Uma epopéia moderna: 80 anos de imigração japonesa no Brasil. São Paulo: Hucitec; Sociedade Brasileira de Cultura japonesa, 1992.

LESSER, J. A negociação da identidade nacional: imigrantes, minorias e a luta pela etnicidade no Brasil. São Paulo: UNESP, 2001.

LONDRES, Cecília. Patrimônio e performance: uma relação interessante. In: GARCIA, Marcos Vinícius Carvalho; GUSMÃO, Rita; TEIXEIRA, João Gabriel L. C. Patrimônio imaterial, performance cultural e (re)tradicionalização. Brasília: ICS/UnB, 2004.

MACIEL, Maria Eunice. Cultura e alimentação ou o que tem a ver os macaquinhos de Koshima com Brillat-Savarin? Horizontes Antropológicos, Porto Alegre, ano 7, n. 16, p. 145156, dez. 2001. 
MINTZ, Sidney W. Comida e antropologia: uma breve revisão. Revista Brasileira de Ciências Sociais, São Paulo, v. 16, n. 47, p. 31-41, 2001.

PORTELLI, Alessandro. Tentando aprender um pouquinho: algumas reflexões sobre a ética na história oral. Projeto História: Revista do Programa de Estudos Pós-Graduados em História e do Departamento de História da PUC-SP, São Paulo, v. 15, p. 13-49, abr. 1997.

SAKURAI, Célia. Imigração tutelada: os japoneses no Brasil. 191 p. Tese (Doutorado em Antropologia) - UNICAMP, Campinas, SP, 2000.

. Romanceiro da imigração japonesa. São Paulo: Sumaré; FAPESP, 1993. (Série Imigração, 4).

SHIGERU, K. Kaigai Ijû to Imin, Hôjin, Nikkeijin. In: KOMAI, H. (Org.). Higashi Ajia no Diasupora. Tokyo: KOBAYASHI Tomoko, 2011. p. 152-175. (Coleção Sôsho Gurôbaro Diasupura).

. Imigração para o exterior e [os conceitos de] imigrante, compatriota e nikkeijin. In: KOMAI, H. (Org.). A diáspora da Ásia oriental. Tóquio: Kobayashi, 2011. p. 152-175. (Coleção Diáspora Global). Disponível em: <http://www.akashi.co.jp/book/b94744. html>. Colaboração na tradução: Prof. Andrei Cunha UFRGS.

SHOJI, Rafael. O budismo étnico na religiosidade nikkey no Brasil: aspectos históricos e formas de sobrevivência social. Rever: Revista de Estudos da Religião, São Paulo, ano 2, n. 4, p. 47-80, 2002.

SILVA, Alexandra Begueristain da. Deus é eles: práticas religiosas familiares dos imigrantes japoneses em Santa Maria/RS. 182 p. Dissertação (Mestrado em Ciências Sociais) - UFSM, Santa Maria, RS, 2013.

SOARES, André Luis R.; GAUDIOSO, Tomoko Kimura. Entre o Japão e o Brasil: religiosidade e diálogos culturais entre os imigrantes japoneses em Santa Maria, RS. In: SIMPÓSIO INTERNACIONAL SOBRE RELIGIOSIDADES, DIÁLOGOS CULTURAIS E HIBRIDAÇÕES, 3, 2009, Campo Grande.

. 50 anos de história: imigração japonesa em Santa Maria, Rio Grande do Sul, Brasil (1958-2008). Itajaí: Mariadocais, 2008.

TAMASO, Izabela. A expansão do patrimônio: novos olhares sobre velhos objetos, outros desafios. Sociedade e Cultura: Revista de Pesquisas e Debates em Ciências Sociais, v. 8, n. 2, p. 13-36, jul./dez. 2005.

WOORTMANN, Klaas. O sentido simbólico das práticas alimentares. In: ARAÚJO, W. M. C.; TENSER, C. M. R. (Org.). Gastronomia: cortes e recortes. Brasília: SENAC, 2006. p. 23-55. 
ZANINI, M. C. C. Italianidade: pertencimento, reivindicações e negociações identitárias na região central do Rio Grande do Sul, Brasil. In: REUNIÓN DE ANTROPOLOGIA DEL MERCOSUL, 6, 2005, Montevidéu. Disponível em: <http://www.fsma.edu.br/ visoes/ed03/3ed_artigo5.pdf>. Acesso em: 10 fev. 2013.

Resumo: Neste artigo, pretende-se evidenciar as narrativas das mulheres japonesas da cidade de Santa Maria no que se refere à gastronomia nipo-brasileira como elemento de etnicidade. Espera-se, principalmente, dar voz às suas memórias, no que tange aos seus saberes culinários, reconhecendo na subjetividade do seu discurso os traços diacríticos que compõem a identidade nipo-brasileira, e demonstrar seu papel e seu modo de viver, agir e pensar na comunidade nikkei de Santa Maria, desde a época da imigração aos dias atuais, seja como mulher, agricultora, esposa, filha ou estudante. São essas peculiaridades da etnicidade que colaboram para a construção da identidade, perpassando a memória do grupo e sendo transmitidas através das geraçôes pela oralidade.

Palavras-chave: cultura japonesa, memória, gastronomia típica, identidade étnica, mulheres japonesas em Santa Maria.

\title{
Nikkei identity and memory: the case of the Japanese women in Santa Maria
}

\begin{abstract}
This article aims to highlight the stories of Japanese women in the city of Santa Maria, in relation to Japanese-Brazilian gastronomy as an element of ethnicity. Mainly, giving voice to memories, in terms of their culinary knowledge, recognizing the subjectivity of the diacritical speech traits that make up the Japanese-Brazilian identity and demonstrate their role in the Nikkei community since the time of immigration to present day, their ways of living, acting, and thinking like a woman, farmer, wife, daughter or student in the Japanese community of Santa Maria. These are the peculiarities of ethnicity that contribute to the construction of identity through the group's memories and are passed down through the generations by oral tradition.
\end{abstract}

Keywords: japanese culture, memory, typical gastronomy, ethnic identity, Japanese women of Santa Maria.

Recebido em 20/11/2012

Aprovado em 26/05/2013 